\title{
UN MODELO FUNERARIO DEL TARDOGÓTICO CASTELLANO: LAS CAPILLAS TREBOLADAS
}

\author{
POR \\ BEGOÑA ALONSO RUIZ \\ Universidad de Valladolid
}

\begin{abstract}
Las capillas treboladas constituyen el modelo centralizado más innovador de cuantos se desarrollan en la España tardogótica. Es de sobra conocido el brillante desarrollo de las grandes capillas funerarias cubiertas con asombrosas bóvedas de crucería estrellada a finales del siglo XV y primeras décadas del siglo XVI de manos de artistas llegados de más allá de los Pirineos para renovar nuestro viejo gótico. Así surgen las grandes capillas funerarias de Toledo o Burgos, a semejanza de las cuales se construirán un sinfín de pequeñas capiIlas en iglesias parroquiales o monasterios por toda la geografía peninsular para todo aquel noble o religioso con pretensiones de pasar a la Historia. Sólo unos pocos arquitectos (vinculados al área segoviana y al influjo de Juan Guas) y patronos (de la alta nobleza castellana y del alto clero) se alejaron de este modelo para arriesgarse por el trebolado, dando como resultado un conjunto muy homogéneo de construcciones levantadas en un arco de tiempo muy limitado.
\end{abstract}

Palabras clave: Arquitectura gótica. S. xv. S. Xvi. Capillas treboladas.

Trefoil chapels constitute the most innovative centralized model of all those developed in late-Gothic Spain. The brilliant unfolding of the great funerary chapels covered by astonishing vaults of star-shaped ribs at the end of the 15th and the first decades of the 16th century, created by artists who had emigrated from the other side of the Pyrenees, has long been recognized. Thus arise the great funerary chapels of Toledo or Burgos, in imitation of which appear an endless number of small chapels in churches and monasteries throughout the Peninsula, for all those nobles or ecclesiastics desirous of becoming a part of history. Only a few architects (pertaining to the Segovian region and to the influence of Juan Guas) and patrons (belonging to the upper Castillian nobility and high clergy), distanced themselves from this model to venture for the trefoil. The result was a highly homogeneous group of structures errected within a limited span of time.

Key words: Gothic architecture. 15th century. 16th century. Trefoil chapels.

Partiendo del carácter excepcional de los templos centralizados en España, dada la axialidad determinada por la función litúrgica del altar mayor con un gran retablo ${ }^{1}$, resulta sorprendente el homogéneo conjunto formado por estas capillas mayores estructuradas en forma de trébol construidas en Castilla entre los siglos Xv y xvI. Aunque el tema ya mereció unas primeras reflexiones de historiadores como Gómez Moreno o Chueca Goitia, no fue hasta los años ochenta y noventa del pasado siglo cuando se hicieron las primeras valoraciones sobre

\footnotetext{
' Marías, F.: «Las iglesias de planta central en España», en L'eglise dans l'architecture de la Renaissance. (Colloque á Tours, 1990), Paris, 1995, pp. 133-146.
} 
el posible origen de esta rara avis, así como los primeros inventarios de los ejemplos españoles ${ }^{2}$. En nuestro primer análisis de la tipología ${ }^{3}$ defendimos ya que el origen último del modelo trebolado (con evidente significado simbólico ${ }^{4}$ ) procedía del mundo paleocristiano que ya había empleado en sus basílicas estas cabeceras en el siglo iv. Habían pasado a la arquitectura románica por su claro simbolismo trinitario (tal es el caso de San Fidel de Cómo, San Vicente en Galiano o Santo Tomás del Limen de Almena). Fue también el románico el encargado de trasladar el modelo a Alemania, donde llegó a través de Lombardía, entonces gobernada por los otones alemanes. Prueba de ello es la existencia en ciudades como Colonia de varias iglesias con este tipo de cabecera pero en versión aún románica (como Santa María en Capitolio y la iglesia de los Santos Apóstoles). Fue en la Catedral de Milán (iniciada en 1387) donde la capilla mayor y los brazos del transepto se remataron ya en ochavos góticos. Sin embargo, en España no existía esta tradición prerrománica; la tipología de cabecera trebolada (aún semicircular) únicamente está representada en la cabecera de la iglesia de San Pedro en Tarrasa (Barcelona) construida entre los siglos x y XI, siendo su cabecera la correspondiente a la parte prerrománica de la iglesia (tres exedras adaptadas a una bóveda ovalada).

Todo ello indica que en Castilla el modelo trebolado a finales del siglo xv suponía una gran innovación, dada la inexistencia de ejemplos de este modelo planimétrico en nuestro país ${ }^{5}$. Puede que en esta falta de referencias esté la razón de la escasa aceptación del modelo: se han encontrado doce ejemplos muy localizados en el espacio y en el tiempo y relacionados con un reducido grupo de arquitectos de primera fila y de promotores del alto clero y la alta nobleza, así como las órdenes reformistas ${ }^{6}$. Este factor es el que explica la gran uniformidad en el tipo de plantas y alzados (Fig. 1).

El problema mayor con el que se enfrenta el análisis de esta tipología es el establecer la vía de entrada del modelo en Castilla, ante la evidente falta de ejemplos anteriores que sirviesen de inspiración. Como un lugar común más, se ha venido manteniendo la relación del modelo con los ejemplos de cabeceras triconques (versión románica del trébol gótico) existentes en Colonia y su llegada a España de manos de arquitectos germanos. Sin embargo, una de las primeras paradojas de la existencia de cabeceras treboladas en nuestro país, es la imposibilidad de relacionarlas con el trabajo de algún arquitecto alemán. Los más famosos artistas alemanes del momento, los Colonia, optaron siempre por el empleo de capillas ochavadas, pero nunca - hasta donde sabemos- treboladas. Creemos que la vía para explicar la introducción del modelo a finales del siglo xv de manos de un artista bretón, Juan Guas, está en las raíces de la tipología desde el mundo paleocristiano adaptado en un principio a funciones funerarias y relacionado en especial con las órdenes reformadas. De hecho, el modo tuvo su éxito como

\footnotetext{
${ }^{2}$ Gómez Moreno, M.: Catálogo Monumental de Ávila y su provincia. (1901), Madrid, 1983, t. 1, pp. 194-197; Chueca Goitia, F.: Historia de la arquitectura española. Edad Antigua. Edad Media. Madrid, 1965, p. 567; Hoag, J.D.: Rodrigo Gil de Hontañón. Gótico y Renacimiento en la arquitectura española del siglo Xvi. Madrid, 1985, pp. 27-28; Marías, F.: El largo siglo xvi. Madrid, 1989, pp. 126-127 y Gómez Martínez, J.: El gótico español en la Edad Moderna. Bóvedas de crucería. Valladolid, 1998, p. 67.

${ }^{3}$ Este trabajo constituye una ampliación y actualización de las reflexiones que esbozamos en Alonso Ruiz, B.: Arquitectura tardogótica en Castilla: los Rasines. Santander, 2003, pp. 160-170.

${ }^{4}$ Bonet Correa, A.: «La capilla de Mosén Rubí de Bracamonte y su interpretación masónica», en Ars Longa, n 2, 1991, p. 8.

${ }^{5}$ Sobre las capillas anteriores véase Yarza Luaces, J.: «La capilla funeraria hispana en torno a 1400», en M. Núñez y E. Portela (Coord.): La idea y el sentimiento de la muerte en la Historia y el Arte de la Edad Media. Santiago de Compostela, 1988, pp. 67-91.

6 Se trata de las iglesias de El Parral, Berlanga de Duero, Villacastín, Guriezo, Casalarreina, La Estrella, Valbuena, Santiago el Real en Logroño, El Espinar, Coca, Capilla de Mosén Rubí y San Francisco de Medina de Rioseco. Weise incluye en este listado la iglesia de Santo Tomás de Haro que no tiene cabecera trebolada, error luego seguido por Hoag. Por su parte Bonet Correa incluye también la iglesia de Santa María de Laguardia (Álava), sin embargo, de cabecera ochavada.
}

$A E A$, LXXVIII, 2005, 311, pp. 277 a 295 


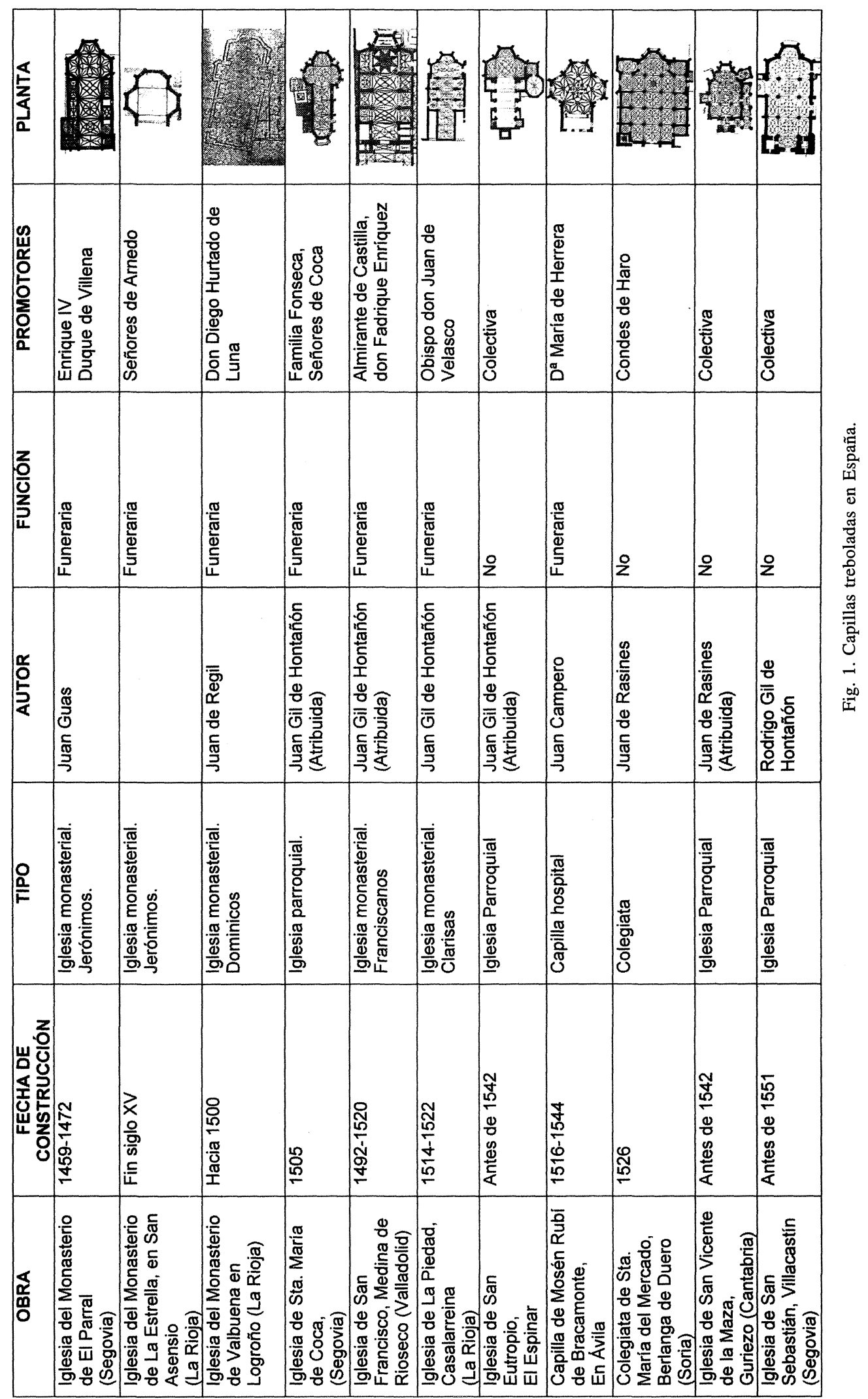

$A E A$, LXXVIII, 2005, 311, pp. 277 a 295 
capilla mayor - funeraria- en monasterios y conventos franciscanos ya que facilitaba el poder disponer de tres ábsides en lugar de uno, como variación del habitual modelo franciscano derivado de la iglesia de Asís ${ }^{7}$.

Estructuralmente el modelo de capilla presenta bastantes complejidades constructivas derivadas de los soportes y responsiones de los tres ochavos. Estos - de muros rectos y contrafuertes en ángulo- se estructuran en torno a un espacio siempre cuadrado que hace las funciones de crucero y se cubren con una sección de crucería, siempre con iguales dimensiones, sin que prime o se favorezca ninguna dirección, creando un espacio interior unitario, desembarazado y sobradamente iluminado. La capilla sobresale en planta, adaptándose a la anchura del cuerpo del templo, generalmente de nave única y capillas hornacinas.

\section{La iglesia del Monasterio de El Parral}

Este monasterio jerónimo es una fundación real iniciada por Enrique IV con la intención de convertirlo en su palacio-monasterio-panteón ${ }^{8}$. Sin embargo, el patronato sobre su capilla pronto pasó a manos de su valido el Maestre de Santiago don Juan Pacheco ${ }^{9}$, que en un primer momento había sido enterrado en Guadalupe junto al monarca y luego fue trasladado al Parral «con suntuosidad y aparato nunca vistos emplear en personas no reales» ${ }^{10}$.

Resulta cuanto menos inverosímil el hecho - repetidamente defendido entre los historiadores del arte- de que durante el primer periodo de patronazgo regio la obra estuviese en manos de un maestro local, Juan Gallego, mientras que a partir de 1472 (año de la cesión al Marqués de Villena) se hace cargo de la misma el arquitecto real Juan Guas, junto a Martín Sánchez Bonifacio - vecino de Toledo, posiblemente familiar de Guas-y Pedro Polido - de Segovia-. Para entonces la capilla mayor estaba ya comenzada y los tres maestros debían continuarla «desde el entablamento» por un precio de 400.000 maravedíes obligándose a acabarla en el plazo de tres años. Para valorar la intervención del arquitecto real en El Parral debemos recordar la enemistad manifiesta existente entre los Villena, especialmente doña Beatriz Pacheco, y la reina católica, que a nuestro entender impediría cualquier tipo de relación del arquitecto con los nuevos «dueños» del Parral. Más lógico resulta pensar que dado el interés que manifestó Enrique IV por la fundación segoviana, su traza sería encargada a un arquitecto de renombre, dejando la construcción del conjunto monasterial en manos de un maestro local como demuestra el hecho de que cuando en 1459 se documenta a Gallego es como maes-

\footnotetext{
${ }^{7}$ Martínez de Aguirre, J.: «Espiritualidad franciscana y arquitectura gótica: del recelo a la rehabilitación», en VI Semana de Estudios Medievales, (Nájera, 1995), Logroño, 1996, pp. 111-131.

8 «...el monasterio del Parral fue pensado como palacio-monasterio-panteón donde encontrar el descanso eterno. Sólo la petición del Marqués de Villena, Juan de Pacheco, su valido, impidió que el proyecto se llevara a cabo, quedando el rey a merced de la caridad de los monjes de Guadalupe en cuya iglesia será finalmente enterrado». Cit. Martínez-Burgos, $\mathrm{P}$.: «Enrique IV, Mecenazgo y utopía en el siglo xv castellano», en Actas IX Congreso Español de Historia del Arte, León, 1992, tomo 1, p.319. La fecha de inicio de la obra varía según los autores consultados entre 1454 y 1459 , siendo ésta última la que tiene base documental. Sobre el monasterio además: Azcárate, J.M.: «El supuesto Bonifacio Guas», en Archivo Español de Arte, XXII, 1949, pp. 83-84; Hernández Ruiz de Villa, R.: «El libro del Parral», en Estudios Segovianos, T. XVIII, n.53-54, 1966, pp.267-434; López Domínguez, M.P. y Barrio Gozalo, M.: El Monasterio del Parral al final del Antiguo Régimen. Segovia, 1987; Mateo, I.; López-Yarto, A. y Ruiz Hernando, J.A.: «El monasterio de Santa María del Parral (Segovia)», en Academia, n.84, 1997, pp. 153-182; Ruiz Hernando, J.A.: El Monasterio de El Parral. León, 1986; Villalpando, M.A y Díaz Moraleda, M.D.: «Dos cartas del marqués de Villena sobre la iglesia del Parral», en Estudios Segovianos, n. 24, 1972, pp. 383-384; Villalpando, M. y Díaz Miguel, M.D.: «Documentos del Monasterio del Parral en el Archivo de la Delegación de Hacienda de Segovia», en Studia Hyeronymiana, 1973; y ahora M. ${ }^{a}$ Blanca López Díez: Segovia en Época de los Trastámara. Tesis Doctoral. U.A.M., 2002.

${ }^{9}$ Se trata del I Marqués de Villena, cabeza de la nobleza castellana en contra del favorito Álvaro de Luna, y casado en primeras nupcias con una hija de don Pedro Fernández de Velasco.

${ }^{10}$ Martínez Adell, A.: «Arquitectura plateresca en Segovia», en Estudios Segovianos, 1955, VII, p. 33.
} 


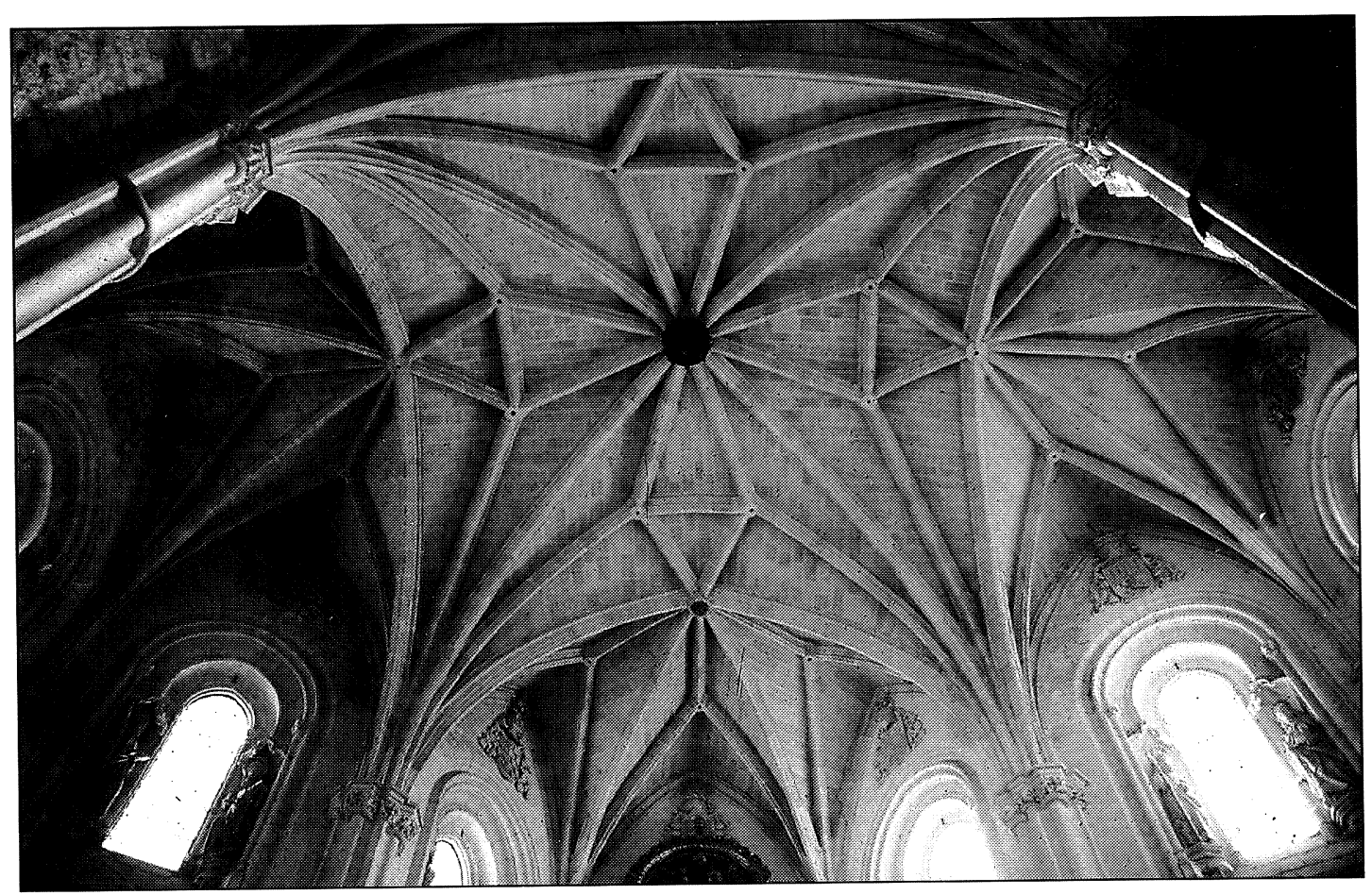

2

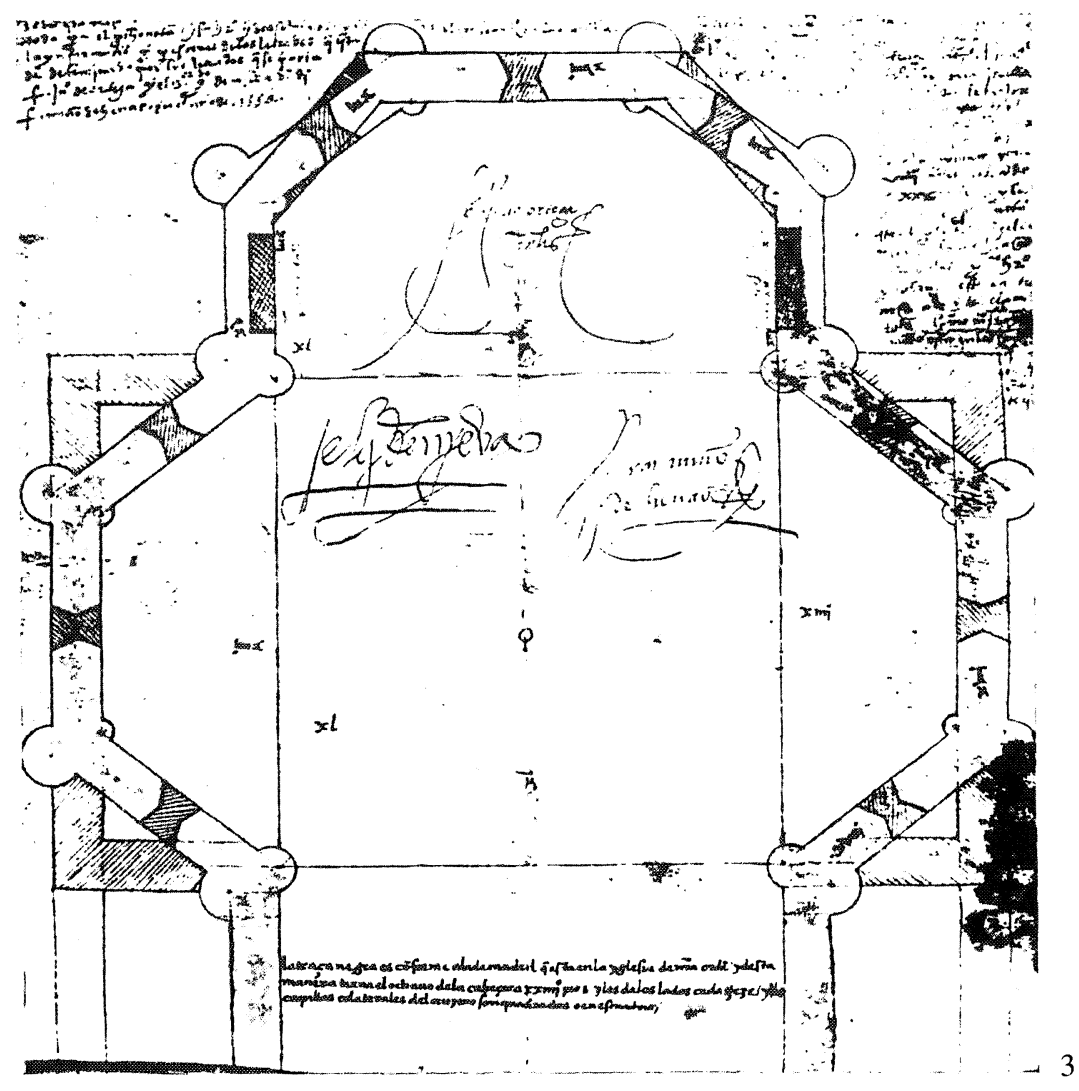

Fig. 2. Cabecera del Parral (Foto. J. Gómez Martínez). Fig. 3. Traza para el Monasterio de La Estrella.

AEA, LXXVIII, 2005, 311, pp. 277 a 295 
tro de la obra del claustro ${ }^{11}$. Con el nuevo patronazgo de los Pacheco, la obra de la capilla debió avanzar a las órdenes de Gallego que seguía trazas de Guas. Luego, los parones de la obra tras la muerte del marqués, la posible muerte de Gallego en $1472{ }^{12}$, y la cercanía del arquitecto - ya en Segovia desde 1471 a cargo del nuevo claustro catedralicio- debieron motivar un nuevo contrato para continuar la capilla con su tracista y dos maestros canteros (el papel de Guas sería el de avalar el contrato, mientras la obra recaía en los otros maestros). La reina, tras la muerte del marqués y su hija, no impidió esta intervención de Guas. De hecho, ya poco le debía importar la capilla funeraria de los Villena si ella misma tenía en mente la construcción de su propio panteón con ese mismo arquitecto, como en efecto hizo a partir de 1476 en San Juan de los Reyes, no escatimando en gastos ${ }^{13}$.

Las gestiones de fray Pedro de Mesa tras la paralización de las obras por muerte del marqués consiguieron que en 1485 se cerrase la capilla, reanudándose la obra de las naves al año siguiente. En 1494 Juan de Ruesga trabajaba en el coro de la iglesia ${ }^{14}$, y hacia 1503 se había concluido la obra. Sebastián de Almohacid contrataba la obra del apostolado de la capilla mayor, más otras dos imágenes que debían ser reconocidas por Juan Guas. Los sepulcros orantes colocados en los muros laterales de la capilla mayor fueron encargados en 1528 por don Diego López Pacheco, cuyo escudo fue colocado en la fachada del monasterio junto al de su mujer Juana Enríquez. Finalmente, Juan Campero en 1529 construía el campanario.

Fue Guas, y no un desconocido Gallego, el que estableció en la capilla mayor del Parral las características principales del modelo trebolado aplicado a un conjunto monasterial y, de hecho, los ejemplos posteriores apenas difieren de esta primera construcción. El maestro bretón articulaba el espacio de la capilla mayor en torno al crucero, único tramo cuadrado del templo que servía de eje modular al mismo. El diseño de las bóvedas (semioctógonos en los ochavos) de ocho puntas en el crucero incidían en la uniformidad de este espacio centralizado, del mismo modo que la articulación mural interior y exterior. El empleo de la luz reforzaba también la centralización en torno a la capilla mayor (único espacio iluminado), del mismo modo que el arco toral separaba la capilla de las naves del templo (existía una reja labrada en 1605 y desaparecida en el siglo XIX). La estructura así concebida resultaba muy adecuada como capilla mayor de las iglesias denominadas conventuales, con una única nave a la que se abren capillejas comunicadas entre sí (Fig. 2).

LOS PRIMEROS ENSAYOS EN LA RIOJA

El modelo segoviano tuvo su eco más inmediato en dos fundaciones religiosas geográficamente alejadas del centro castellano. Resulta paradigmático que se impusiera como el modelo para construir la capilla del monasterio jerónimo de La Estrella en San Asensio (La Rioja) a

\footnotetext{
${ }^{11}$ Hernández, A.: «Juan Guas, maestro de las obras de la Catedral de Segovia (1471-1491)», en Boletín del Seminario de Arte y Arqueología, XLV, 1947-48, p. 75.

${ }^{12}$ Seguimos a López Domínguez, M.P. y Barrio Gozalo, M.: El Monasterio del Parral al final del Antiguo Régimen. Segovia, 1987 , p. 16.

${ }^{13}$ Guas le contó al viajero Münzer en 1495 que en la obra ya se llevaban invertidos 200.000 ducados. (García Mercadal, J.: Viajes de extranjeros por España y Portugal. Madrid, 1952, p. 401. Cit. Martínez de Aguirre, J.: «Espiritualidad franciscana...», p. 111). Entre 1480 y 1504 las cantidades libradas para la construcción y funcionamiento fueron 16 millones de maravedíes (Yarza Luaces, J.: Los Reyes Católicos. Paisaje artístico de una monarquía. Madrid, 1993, p. 43).

${ }^{14}$ Escritura de obligación del 19 de julio de 1494 por la que Ruesga se obligaba a deshacer el coro del Parral y rehacerlo más elevado con la condición de «guardar el mismo orden que la bóveda de la iglesia», por precio de 125.000 maravedíes y para las próximas navidades. (Cit. Bosarte, I.: Viaje artístico. Apéndice Documental, I: Noticia de las escrituras que se conservan en el archivo del Real Monasterio de Santa María del Parral de Segovia de las obras pertenecientes al monasterio. Pp. 353-354).
}

$A E A$, LXXVIII, 2005, 311, pp. 277 a 295 
finales del siglo xv y a mediados de la siguiente centuria el proyecto se reformase tomando entonces el modelo de la casa madrileña, que no es otro que el de San Juan de los Reyes. Esta información nos la proporciona una traza realizada en 1564 por el maestro Francisco Martínez de Goicoa para adaptar la antigua capilla como nuevo enterramiento de los Señores de Arnedo (de la familia Velasco y después Condes de Nieva) ${ }^{15}$. La traza recoge el proyecto trebolado que en este momento debe ser reformado: «la traça negra es conforme a la de Madrid que esta en la yglesia de nuestra orden». De hecho, la capilla trebolada parece que no se llegó a construir; la fundación de don Sancho de Velasco en su testamento de 1493 se fue dilatando en el tiempo, de tal manera que en 1501 el condestable don Bernardino daba un plazo de tres años a los descendientes de Velasco, los Condes de Nieva, para comenzar la capilla que aún en 1552 no se había iniciado. Cuando por fin se decidió comenzar la obra, la traza trebolada fue desestimada a favor de una capilla ochavada con crucero de brazos rectos. Dado que no tenemos información sobre el primer proyecto trebolado resulta demasiado arriesgado el aventurar el nombre de su posible arquitecto, si bien parece obvia la vinculación con el modelo del Parral a que en esta ocasión se le añade un nuevo tramo rectangular entre el ochavo del altar mayor y el crucero para albergar lucillos sepulcrales, una solución que veremos repetida en Santa María de Coca (Fig. 3).

Cronológica y geográficamente cercano al proyecto trebolado de La Estrella, se sitúa el del convento dominico de Valbuena en la ciudad de Logroño (La Rioja). Fue construido por el maestro Juan de Regil con anterioridad al año 1500. La fundación se debe también al patronato de un destacado linaje, en este caso el de los Luna, y en concreto a don Diego Hurtado de Luna, entonces capitán de los tercios de la corona castellana en la ciudad de Logroño ${ }^{16}$. La fundación parece estar relacionada con el interés de los Luna, Señores de Cornago y Jubera, de vincularse con el entonces pujante centro comercial que suponía la ciudad de Logroño, ampliando así su influencia más allá de sus territorios entre Castilla y Aragón ${ }^{17}$. En esencia, la iglesia de Valbuena (o Valcuerna, según se denominaba en la época) es un templo de cabecera trebolada pero, a diferencia de los modelos que hemos visto y veremos, su espacio interior no se aprecia como trebolado o triple, sino que se cubre con una única bóveda de crucería, sugiriendo un gran espacio centralizado. El modelo de la bóveda es de directa inspiración segoviana, con nervios rectos a modo de Guas, pero el desarrollo de la única nave del templo difiere del resto de los ejemplos que estudiaremos, ya que en Logroño fue necesario trasdosar el transepto al resultar poco profundas las capillas hornacinas. Estamos ante lo que podríamos considerar un ensayo sobre el modelo segoviano de El Parral, realizado por un prácticamente desconocido maestro llamado Juan de Regil al que, sin embargo, debemos vincular con la corriente más innovadora de la arquitectura tardogótica castellana por su trabajo en la nueva iglesia de Santa María la Redonda de Logroño (La Rioja) ${ }^{18}$. En este caso se inclinó por trazar una iglesia salón, elección que en 1516 suponía una declaración de principios, ya que el modelo salón se impondrá a partir del debate suscitado en 1523 con motivo de la continuación de

\footnotetext{
${ }^{15} \mathrm{La}$ traza fue publicada por Cadiñanos Bardeci, I.: «El monasterio de La Estrella y Navarrete el Mudo», en Academia, 63, 1986, pp. 265 y ss. Lám. II. (AHN, Secc. Clero, carp. 1062). Goicoa formaba parte de un numeroso grupo de maestros de cantería de procedencia vasca (su hermano Juan Martínez de Goicoa, los Martínez de Mutio, Pérez de Solarte, etc.) que trabajaron en muchas obras del Obispado de Osma, La Estrella, Santo Domingo de la Calzada (Briñas, Tirgo) y que también trabajaron en la Colegiata de San Pedro de Soria y Santa María de Belorado (Burgos).

${ }^{16}$ Debemos agradecer a Juan Manuel Tudanca la información proporcionada sobre el convento, ahora en fase de restauración. Ahora véase Álvarez Clavijo, M. ${ }^{a}$ T.: Arquitectura religiosa en la ciudad de Logroño en el siglo xVI. Logroño, 2003, Tomo II, pp. 347 y ss.

${ }^{17}$ Sobre los Luna véase: Moya Valgañón, J.G.; Ruiz, J.; Arrue, B.: Castillos y fortalezas de La Rioja. Logroño, 1990, pp. 129-134.

${ }^{18}$ Hasta ahora nada más se conocía sobre la obra de Juan de Regil; puede que estuviera emparentado con el Martín de Regil que en 1541 trabajaba en la Lonja de Zaragoza. Cit. Barrio Loza, J.A. y Moya Valgañón, J.G.: «Los canteros vizcaínos (1500-1800)», en Kobie, $\mathrm{n}^{\circ} 11,1981$, p. 254. Sobre La Redonda véase: Moya Valgañón, J.G.: Arquitectura religiosa del siglo xVI en La Rioja Alta. 1980, T. II, pp. 84-85.
} 
las obras de la Catedral Nueva de Salamanca ${ }^{19}$. Juan de Regil también fue el maestro cantero de la iglesia logroñesa de Santiago el Real, comenzada a partir de 1513 siguiendo su cabecera una disposición muy similar a Valbuena. Al exterior se trasdosan los tres ochavos,mientras que al interior el espacio de la capilla se cubre con una única gran bóveda estrellada con nevios curvos ${ }^{20}$. Por sus ensayos en Logroño con estructuras centralizadas y por su interés por los espacios diáfanos de la iglesia salón debemos suponerle un conocimiento de lo que estaba ocurriendo en el entorno de Juan Gil de Hontañón, verdadero artífice del relativo éxito que alcanzaron ambos modelos espaciales.

\section{JUAN GIL Y LA DIFUSIÓN DEL MODELO}

Las escasas referencias documentales sobre la arquitectura de finales del siglo xv y primer cuarto del siglo Xvi no aclara mucho sobre las siguientes construcciones treboladas. Significativamente son Juan Gil de Hontañón y Juan Campero, arquitectos formados a la sombra de Guas en el área segoviana, los tracistas documentados ${ }^{21}$.

El 15 de octubre de 1505 Juan Gil firmaba con el obispo Juan Rodríguez de Fonseca el contrato para la construcción del claustro y la sala capitular de la catedral de Palencia ${ }^{22}$. El nuevo obispo aún no había hecho su entrada en la diócesis pero entre sus primeras decisiones estuvo la de disponer de arquitectos de su confianza al frente de las diferentes obras que debían acometerse en la nueva catedral gótica. Primero fue Juan Gil, con quien firma el contrato en Coca (Segovia); luego fue Juan de Ruesga — «muy buena persona y buen maestro»- el 27 de abril de 1506 para las obras de las naves ${ }^{23}$. Como testigo en este documento figura el tercer arquitecto involucrado en la obra palentina: Martín de Bruselas o «maestre Martín», «criado de Su Señoría» a quien acompaña desde su regreso de Flandes y que en esta ocasión ejercerá de veedor de las obras de la catedral ${ }^{24}$. Lo significativo en este caso es que el obispo (muerto en 1523, promotor de la Escalera Dorada y la Puerta de la Pellejería de la catedral de Burgos), formaliza el contrato con Juan Gil en su villa, hecho explicable desde la perspectiva de que Gil fuese el encargado de construir la iglesia parroquial de Santa María, iglesia-panteón de los Fonseca.

La obra debió comenzarse al poco de la muerte del hermano mayor del obispo, don Alonso de Fonseca Avellaneda, acaecida el 7 de agosto de ese año de 1505. De hecho, don Alonso (III Señor de Coca) había impulsado su construcción, obteniendo para ello una bula papal poco antes de su muerte ${ }^{25}$. A partir de entonces los hermanastros del difunto, el obispo don Juan y don Antonio de Fonseca Ayala (Contador mayor de Castilla y IV Señor de Coca), debieron acometer la construcción de su panteón familiar aprovechando el encargo real de ocuparse de los sepulcros de la Capilla Real de Granada. De hecho, ambas obras compartirán arquitectos y escultores; es de sobra conocida la intervención del taller hispano-italiano de Carrara (Bartolo-

\footnotetext{
${ }^{19}$ Sobre el modelo salón véase Alonso Ruiz, B.: Arquitectura Tardogótica... pp. 107-130.

20 Álvarez Clavijo, M. ${ }^{a}$ T.: Arquitectura religiosa..., T. II, pp. 248 y ss.

${ }^{21}$ Alonso Ruiz, B.: «Juan Gil de Hontañón en Segovia: sus comienzos profesionales», en Boletín del Seminario de Estudios de Arte y Arqueología, Valladolid, 2000, LXVI, pp. 153-162.

${ }^{22}$ García Cuesta, T.: «La catedral de Palencia según los protocolos», en Boletín del Seminario de Arte y Arqueología, Valladolid, 1953-54, XX, pp. 102-104, doc. 10.

${ }^{23}$ Id., doc. 7.

${ }^{24}$ Vasallo Toranzo, L.: «El arquitecto maestre Martín», en El arte español en épocas de Transición. Actas IX Congreso Nacional de Historia del Arte, León, 1992, pp. 343-351.

${ }^{25}$ Rodríguez Martínez, F.A.: «Los Fonseca y sus mausoleos en la villa de Coca», en Armas e Troféus, V Serie, T.VI, 1987, pp. 14-15. Sobre la iglesia también: Martínez Adell, A.: «Arquitectura plateresca...», pp. 5-56; Moreno Alcalde, M.: «Los Fonseca y la iglesia de Santa María de Coca», en Anales de Historia del Arte, 1990, pp. 57-77 y Rodríguez Martínez, F.: Historia de Coca. (Estudio y documentos). Segovia, 1993.
} 
mé Ordóñez y Domenico Fancelli) en los sepulcros ${ }^{26}$ pero además resulta curiosa la coincidencia de que los tres arquitectos de confianza de Fonseca sean los que acudan en 1512 a informar sobre la marcha de la obra granadina ${ }^{27}$. En el taller de Ordóñez se trabajaba en los sepulcros de los hermanos Fonseca en diciembre de 1520 y Fancelli realizaba el de don Fernando - su padre y maestresala de Enrique IV, muerto en la batalla de Medina en 1463-y su segunda esposa Teresa de Ayala. Fueron dispuestos en su ubicación actual en 1532, el año de la muerte de don Antonio y, puede, que coincidiendo con el final de las obras de la iglesia ${ }^{28}$.

La iglesia de Coca representa uno de los escasos ejemplos de la tipología en que todos los muros rectos de la cabecera trebolada se han empleado como sepulturas e incluso se han abierto arcosóleos en los ochavos que sirven de crucero. Estructuralmente el edificio se diferencia muy poco del modelo precedente, aunque es digna de destacar la existencia de un contraábside, también ochavado, a los pies del templo como solución compositiva encargada de equilibrar el templo ${ }^{29}$. La bóveda de sencillo cuatrifolio sobre el crucero nos remite a las bóvedas de la sala capitular palentina, realizadas por Juan Gil. La articulación de los soportes, con basa circular de penetraciones y fuste moldurado, nos remiten también a otra obra relacionada con el maestro Hontañón, La Piedad de Casalarreina (Fig. 6).

También está relacionada con los años palentinos de Juan Gil de Hontañón el Convento de San Francisco en Medina de Rioseco (Valladolid), entonces dependiente de ese obispado. Aunque no se ha localizado documentación que lo confirme, la iglesia franciscana está relacionada estilísticamente con el maestro cántabro como ya puso de manifiesto García Chico ${ }^{30}$. No sólo nos encontramos ante una obra que repite modelos de bóvedas directamente inspirados en el claustro palentino, sino que su tipología de cabecera trilobulada nos remite directamente a Juan Guas y el monasterio de El Parral y a la planta de la iglesia de Coca. A todo esto debemos unir el hecho de que el promotor en este caso era el almirante Fadrique Enríquez (m. 1538), hijo de María de Velasco ${ }^{31}$, sobrino del condestable don Pedro y primo de Mencía, la fundadora del monasterio que Juan Gil trazó en Briviesca (Burgos) e inició en $1512^{32}$. La obra medinense es

\footnotetext{
${ }^{26}$ Han sido perfectamente estudiados los sepulcros de Coca desde que Pietro Andrei publicase el testamento de Bartolomé Ordóñez y G. Campori el inventario de su taller. Luego se han ocupado de estas esculturas historiadores como Justi, Madrazo, Martí y Monsó, Gómez-Moreno o M.E. Gómez-Moreno. Lo último en Sagarra Gamazo, Adelaida (Coord.): Juan Rodríguez de Fonseca: su imagen y su obra. Universidad de Valladolid, Instituto de Estudios de Iberoamérica y Portugal, 2005.

${ }^{27}$ El documento sobre la visita a Granada de los tres maestros fue dado a conocer por Martí y Monsó, J.: Estudios Histórico-Artísticos relativos principalmente a Valladolid. Valladolid, 1901, p. 78. La relación de los tres maestros de la catedral palentina con la capilla de Granada ya había sido resaltada en Agapito y Revilla, J.: «Para la historia de la iglesia mayor de Valladolid», Boletín de la Sociedad Española de Excursiones, 1942, p. 221.

${ }^{28}$ Durante los años 1514 y 1520 existen indicios documentales de que el señorío de Coca estuvo en manos de Rodrigo de Vivar y Mendoza, I Marqués de Zenete, casado con María de Fonseca, hasta que el señorío vuelve a manos de don Antonio en 1521. Se ha sugerido la posibilidad de que las obras renacentistas del castillo de Coca tengan que ver con el marqués y su palacio de La Calahorra (Villanueva, O.: Colección de azulejería del castillo de Coca. Valladolid, 2001, pp. 17-25). No parece que el paso del Mendoza por el señorío afectase a las obras de la iglesia en marcha desde hacía diez años.

${ }^{29}$ El contraábside nos remite a los ejemplos hispanogodos y neovisigodos como el panteón real de Santa María de Oviedo, pero en Coca no se ha empleado con función funeraria, centrada ésta en su capilla mayor trebolada (Véase Bango Torviso, I.: «El espacio para enterramientos privilegiados en la arquitectura medieval española», en Anuario del Departamento de Historia y Teoría del Arte, U.A.M., Vol. IV, 1992, pp. 100 y ss.).

${ }^{30}$ García Chico, E.: Catálogo Monumental de la provincia de Valladolid, I. Medina de Rioseco. Valladolid ( $2^{a}$ edic., 1960), pp. 141-165. En la primera edición el autor se la adjudica al arquitecto Juan Gil de Hontañón. También Torres Balbás, L.: «Medina de Rioseco, la capilla de los Benavente y otros edificios distinguidos», en Arquitectura, 1922, n. 33, pp. 103 y ss.; García Chico, E.: La orden franciscana en Medina de Rioseco. (Ed. facsímil del artículo publicado en el Boletín de la Academia de Bellas Artes de Valladolid, n. 15, 1936, pp. 26-48, n. 16, 1944, pp. 1-27, n. 17, 1945, pp. 1446) Valladolid, 1991 y Muñoz García, A.: Medina de Rioseco. La ciudad de los Almirantes. Valladolid, 1999.

${ }^{31}$ María de Velasco, hija de don Pedro Fernández de Velasco y Beatriz Pimentel, se casó con el III Almirante de Castilla don Alonso (m. 1485) y fue acompañante de la reina doña Juana a Flandes, falleciendo en Palencia en 1505. Su testamento se otorgó en dicha ciudad el 6 de mayo de 1505 y en él mandaba sepultarse en Santa Clara de Palencia «en la sepultura de mi señor el almirante, que Dios haya, donde su merced esta sepultado». Cit. Simón Nieto, F.: Los antiguos campos góticos. Excursiones histórico-artísticas a Tierra de Campos. Palencia, 1998 (1ª edic. Madrid, 1895), p. 53.

${ }^{32}$ Alonso Ruiz, B.: Arquitectura tardogótica..., p. 181.
} 


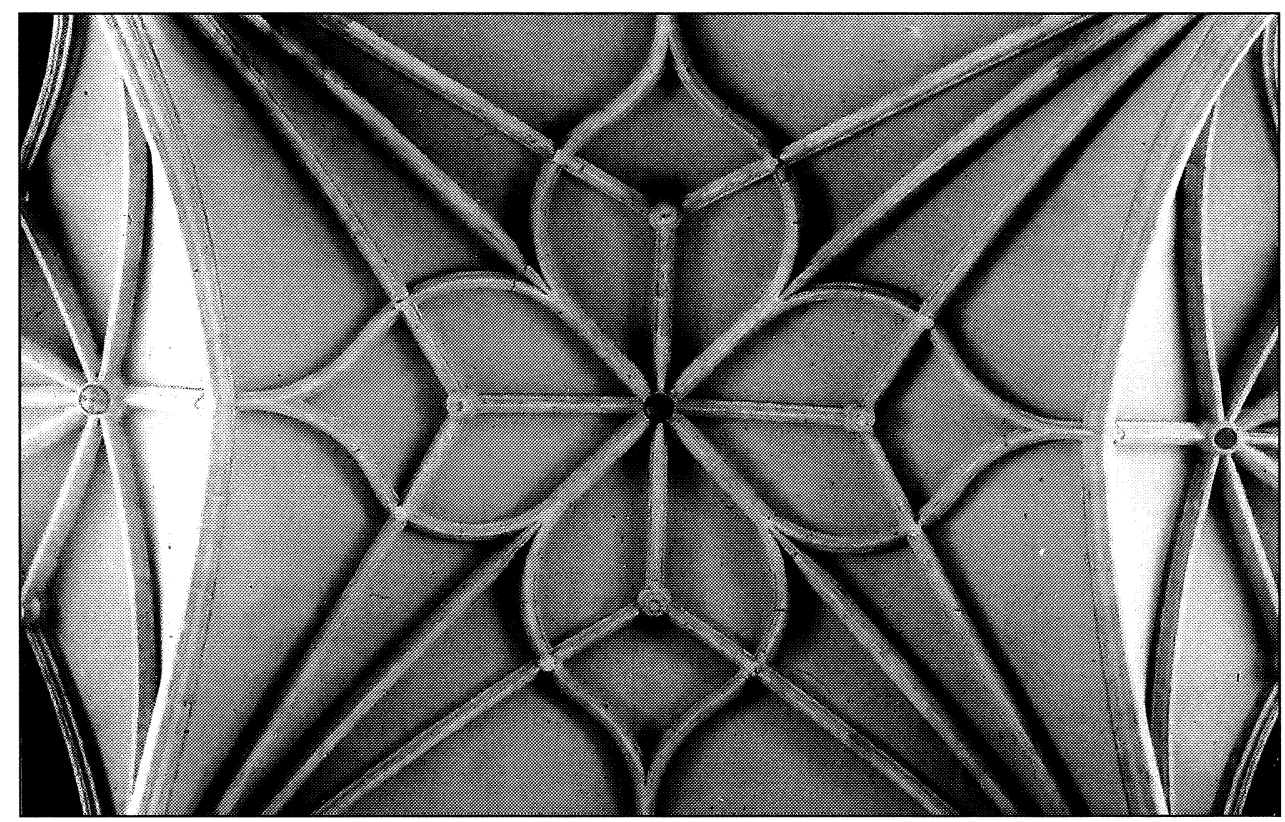

4

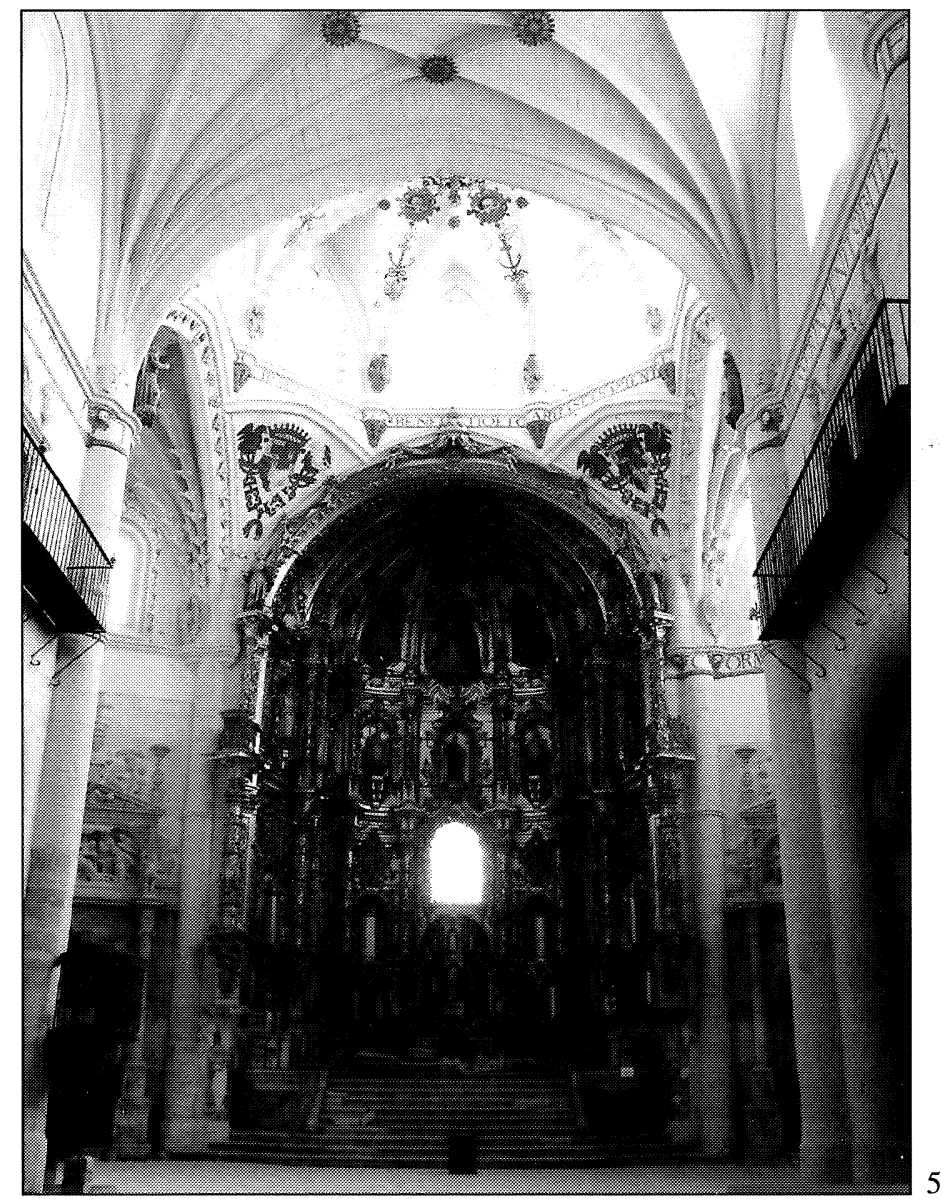

Fig. 4. Cabecera de la iglesia de Coca.

Fig. 5. Interior de San Francisco en Medina de Rioseco.

$A E A$, LXXVIII, 2005, 311, pp. 277 a 295 
anterior; la carta apostólica autorizando su fundación está fechada el 12 de agosto de 1491; en 1492 colocaba la primera piedra el obispo de Termópilas fray Alonso de Espina; al año siguiente se enterraba de manera provisional en su capilla mayor a doña Isabel de Cabrera, Condesa de Melgar y en 1520 el templo era bendecido por Fray Antonio de Garay ${ }^{33}$. En 1514 se trabajaba en la sillería del coro. Catorce años después se hacían las vidrieras, Cristóbal de Andino labraba la reja de la capilla mayor (hoy en la iglesia de Santa María) y Miguel de Espinosa proyectaba para los muros laterales dos altares de piedra con decoración a lo romano (en uno de ellos se lee la fecha de 1535$)^{34}$. En 1532 se colocaba el retablo adaptándolo al ochavo de la capilla mayor ${ }^{35}$. De las capillas de la claustra se tienen más noticias; se sabe que en 1513 se habían concluido varias y que fueron entregadas a familias pudientes de la villa. Una era la del mercader Juan Espinosa, quien el 14 de diciembre pagaba a los canteros Juan Ochoa y Fernando de Haro - vecinos del lugar - 56.000 maravedíes más otros 200 de una ventana que hicieron sin estar obligados a ello. El contador Pedro de Montesa había entregado ese mismo mes al monasterio 34.000 maravedíes «por la capilla que hizo en dicho monasterio» ${ }^{36}$. En 1538 la obra debía continuar, pues el testamento del fundador legaba la nada despreciable cantidad de 1.000 .000 de maravedíes para la labra del monasterio ${ }^{37}$. El lienzo del claustro de arcos de medio punto fue labrado en 1534 tal vez - también según García Chico- por el cantero Juan de Corral ${ }^{38}$.

En la segunda edición del texto de García Chico, éste rectificaba la autoría de la obra, señalando esta vez que probablemente fuesen dirigidas por el maestro de cantería Rodrigo de Astudillo ${ }^{39}$, sustituto de Bartolomé de Solórzano en la mesa capitular palentina a partir de 1509. Pero Astudillo no fue el tracista, quizá el constructor. La intervención de Juan Gil en Medina probablemente coincida con su llegada a la obra de la catedral de Palencia o esté relacionada con la construcción para el obispo de su iglesia de Coca, donde sabemos que se encontraba en octubre de 1505. Resulta evidente que el modelo de bóvedas empleado en las capillas hornacinas del templo riosecano está en el claustro palentino, del mismo modo que la capilla de Santa Isabel (de los Espinosa) reproduce la de la sala capitular palentina; pero la mayor evidencia es sin duda la filiación de su planta, un raro ejemplo de capilla mayor trebolada que ya hemos tenido oportunidad de analizar al hablar de Coca. Para el caso riosecano se ha puesto de manifiesto que la función funeraria de este austero templo franciscano motivó el desarrollo de su cabecera con un crucero de espléndida ornamentación, individualizado gracias a la reja de Andino, del mismo modo que había ocurrido en la iglesia de La Magdalena de Medina del Campo, fundación del mercader Rodrigo de Dueñas ${ }^{40}$. Sea como fuere - esperemos que la documentación acabe desvelando lo ocurrido-, la mano de Juan Gil se aprecia en la traza de la sobria iglesia franciscana y en el diseño de algunos elementos como las bóvedas; su papel debió limitarse al

\footnotetext{
${ }^{33}$ Blanco Martín, F.J.: Proyecto básico y de ejecución de rehabilitación de la iglesia del Convento de San Francisco de Medina de Rioseco. Ayuntamiento de Medina de Rioseco, 1999.

${ }^{34}$ Cristóbal de Villalón vio la reja en 1539 y la calificó de «obra que excede los Siete milagros del mundo». (Gallego de Miguel, A.: «La obra que excede los Siete milagros del mundo. Cristóbal de Andino, escultor y rejero», en Semana Santa. Medina de Rioseco, n. 9, 1996, s/p.). En 1532 Andino rogaba al almirante que diese orden sobre la obra del pavimento. (García Chico, E.: El arte en Castilla. Los templos riosecanos. Valladolid, 1955, p. 60). Restos de vidrieras (con la fecha de 1528) se conservan en la capilla del hospital (Martí y Monsó, J.: «El Convento de San Francisco», en Medina de Rioseco. Semana Santa, 1995, s/p.).

${ }^{35}$ García Chico, E.:La ciudad de los Almirantes. Su historia y tesoro artístico. Valladolid, 1945, p. 142.

${ }^{36}$ A.H.P.Va., Protocolos Notariales, Lorenzo de Arévalo, Leg. 8433, fols. 521 vto., 527 vto. Castán Lanaspa, J.: Arquitectura gótica religiosa en Valladolid y su provincia (siglos XIII-XVI). Valladolid, 1998. También Redondo Cantera, M.J. y Pérez de Castro, R.: «Las capillas del convento de San Francisco», en Medina de Rioseco. Semana Santa 1999, n. 12, s/p.

${ }^{37}$ A.R.Ch.V., Pleitos Civiles, Moreno, Fenecidos, C.1509-3. Documentación Histórica de la Fundación Marcelino Botín.

${ }^{38}$ García Chico, E.: El arte en Castilla..., p. 64.

${ }^{39}$ García Chico, E.: Catálogo Monumental..., p. 141. Astudillo está documentado entre 1479 y 1516 al servicio de la catedral de Palencia.

${ }^{40}$ Castán Lanaspa, J.: Arquitectura gótica religiosa..., p. 393.
} 
de tracista sin encargarse de la construcción, que posiblemente quedaría a cargo de algún capacitado maestro del círculo de la catedral palentina. Probablemente estemos ante una obra realizada por Bartolomé de Solórzano, entonces maestro mayor de la catedral y documentado en la villa de los almirantes. De hecho el 19 de septiembre de 1484 los alcaldes y justicias de la ciudad de Palencia y Medina de Rioseco ordenaban se guarde a Bartolomé de Solórzano, vecino de Medina e hidalgo de padre y abuelo, los privilegios de su condición de hidalgo; aún en 1509 su criado Rodrigo de Escalante seguía avecindado en Medina ${ }^{41}$. En 1516 su hijo Gaspar de Solórzano se comprometía a concluir la obra del templo riosecano de Santa María «vista las muestras e condiciones que la dicha yglesia tiene de los maestros antepasados» ${ }^{42}$. Las referencias estilísticas de esta intervención las encontraríamos en el aspecto «gótico» de toda la obra: pilares semicilíndricos embutidos en el muro, sin basas ni capiteles, roscas lisas de los arcos, el empleo de escarzanos, capiteles decorados con bolas y arcos rebajados en el claustro dispuesto en el lado sur del templo (hoy como arquería del ayuntamiento) ${ }^{43}$ (Fig. 5).

La presencia documentada de Juan Gil de Hontañón en la siguiente capilla trebolada, la iglesia del monasterio de la Piedad de Casalarreina (La Rioja), arroja mucha luz sobre las vías de difusión del modelo por tierras riojanas y cántabras. El monasterio era una fundación del obispo don Juan de Velasco (1465-1520), hijo ilegítimo de don Pedro Fernández de Velas$\mathrm{co}^{44}$. Mientras residió en el Palacio de Casalarreina, desde donde ejercía su dignidad de obispo de Calahorra-La Calzada, en 1509 dispuso en su testamento la cantidad de 12.000 ducados de oro para la construcción del monasterio. El proyecto debió realizarse entre esa fecha y junio de 1513 en que don Juan compraba el terreno necesario para su fundación, colocándose la primera piedra un año más tarde ${ }^{45}$. $\mathrm{Al}$ concedérsele en 1516 la mitra palentina, sus estancias en Casalarreina se espaciaron; estaba en tierras riojanas cuando otorgó su segundo y definitivo testamento el 20 de abril de 1519, en el que encargaba a su heredero el que «mi cuerpo sea sepultado en la Capilla Maior del Monasterio de Nuestra Señora de la Piedad que Yo hago en el Logar de la Cassa de la Reyna y que por la sepultura que compren de Juro y Censos treze mil marabedis e porque me digan cada día para siempre en la dicha Capilla Maior una Missa rezada por mi alma. Ytem mando que sobre mi sepultura no se ponga tumba alta sino solo la piedra negra y en la dicha piedra se ponga unas letras esculpidas que digan: «O Jesús no mires mis males porque no olvides tu nombre» ${ }^{46}$. El monasterio fue solemnemente inaugurado en 1522 , dos años después de la muerte del obispo, por el futuro papa Adriano VI en su viaje hacia Roma ${ }^{47}$. El 22 de octubre de ese mismo año los herederos del obispo capitulaban en Vallado-

\footnotetext{
${ }^{41}$ La noticia de 1484 en A.G.S., R.G.S., Registros normales, VI-1484, fol. 84. (Documentación Histórica de la Fundación Botín); la referencia de Rodrigo de Escalante en Vasallo Toranzo, L.: «Bartolomé de Solórzano. Nuevos datos y obras», en Boletín del Seminario de Arte y Arqueología, Valladolid, LXVI, 2000, p. 169.

${ }^{42}$ García Chico, E.: El arte en Castilla..., p.10.

${ }^{43} \mathrm{La}$ posterior ruina del cimborrio, los informes y peritajes de su reconstrucción pueden seguirse en Martí y Monsó, J.: Estudios Histórico-Artísticos..., p. 489.

${ }^{44}$ Sobre el monasterio véase Weise, G.: Studien zur Spanische Architektur der Spätgotik. Reutlingen, 1933; Lope Toledo, J.M.: «Don Íñigo Fernández de Velasco y el convento de la Piedad de Casalarreina», en Berceo, VIII, 1953, pp. 255270; Inventario artístico de Logroño y su provincia. Vol.1, Madrid, 1975, pp. 294-298; Moya Valgañón, J.G.: Arquitectura religiosa del siglo XVI en La Rioja Alta. Logroño, 1980 y Gil de Zúñiga, R.: Monasterio de La Piedad (Casalarreina) a través de las fuentes escritas de su archivo (monografía histórica). Casalarreina, 1990. Sobre Felipe de Bigarny y el monasterio: Río de la Hoz, I.: El escultor Felipe de Bigarny (h.1490-1542). Valladolid, 2001.

${ }^{45}$ Gil de Zúñiga, R.: Monasterio de La Piedad..., p. 51.

${ }^{46}$ Testamento y codicilos de don Juan de Velasco en A.H.N.Secc. Nobleza, Frías, Leg. 97, antiguo, exp.15.

${ }^{47}$ En 1524 se hace referencia a la «escultura de jaspe que agora se haze para el señor obispo no esta acavada ny hecha en perfecion». Desconocemos el paradero de esta escultura que contravenía las cláusulas testamentarias del obispo. (A.H.N. Secc. Nobleza, Frías, Leg. 99, antiguo, exp. 14, 24-X-1524). El cuerpo del obispo fue finalmente trasladado a la capilla mayor del monasterio en 1529, donde hoy día se puede observar el sencillo sepulcro de piedra llana. El mármol fino de Carrara fue comprado por don Pedro Fernández de Velasco a Juan de Lugano, comerciante, el 6 de julio de 1555 y el epitafio fue colocado el 12 de noviembre de 1594 (Gil de Zúñiga, R.: Monasterio de La Piedad..., pp. 96-114).
}

$A E A$, LXXVIII, 2005, 311, pp. 277 a 295 


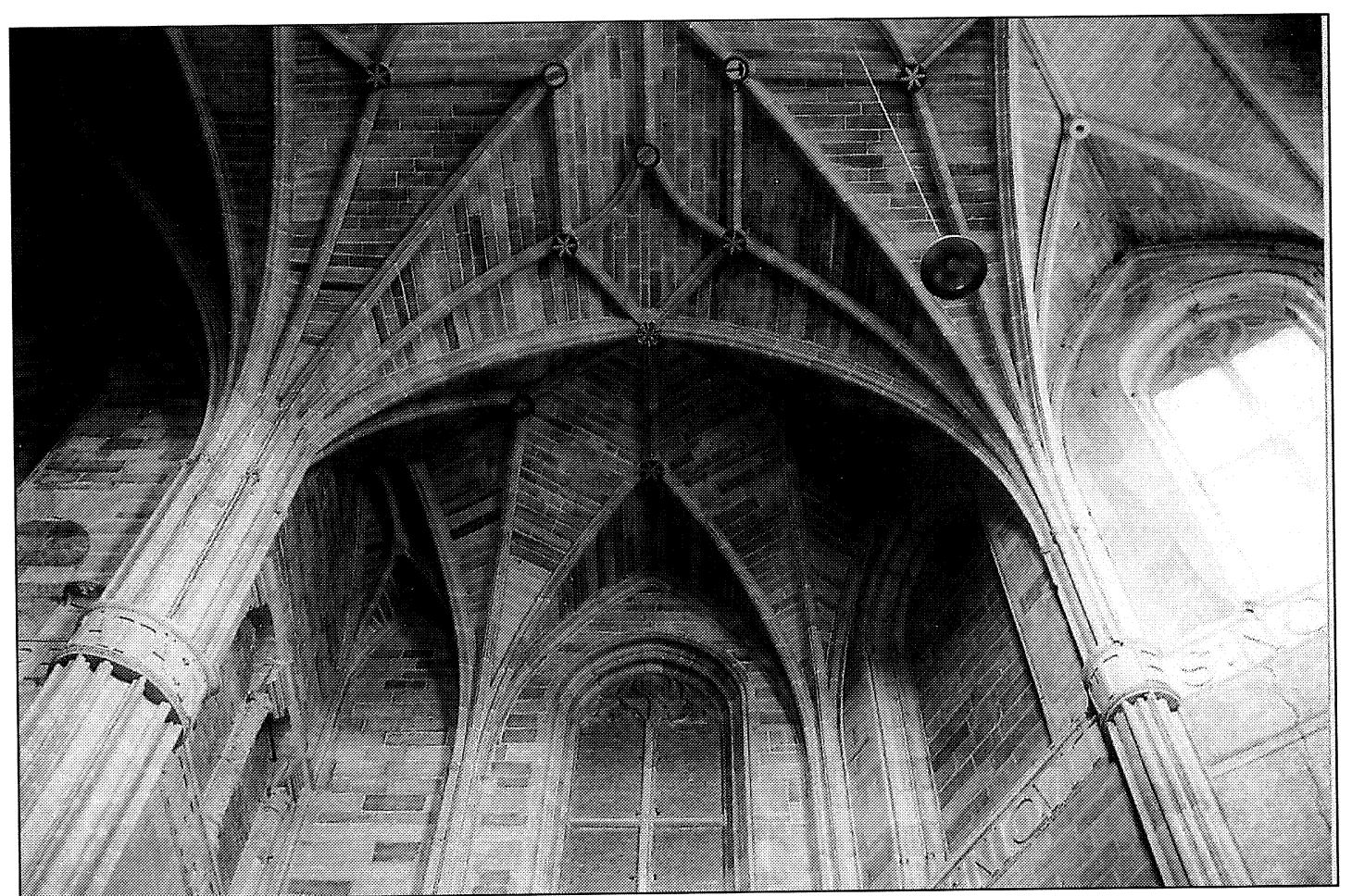

6

7

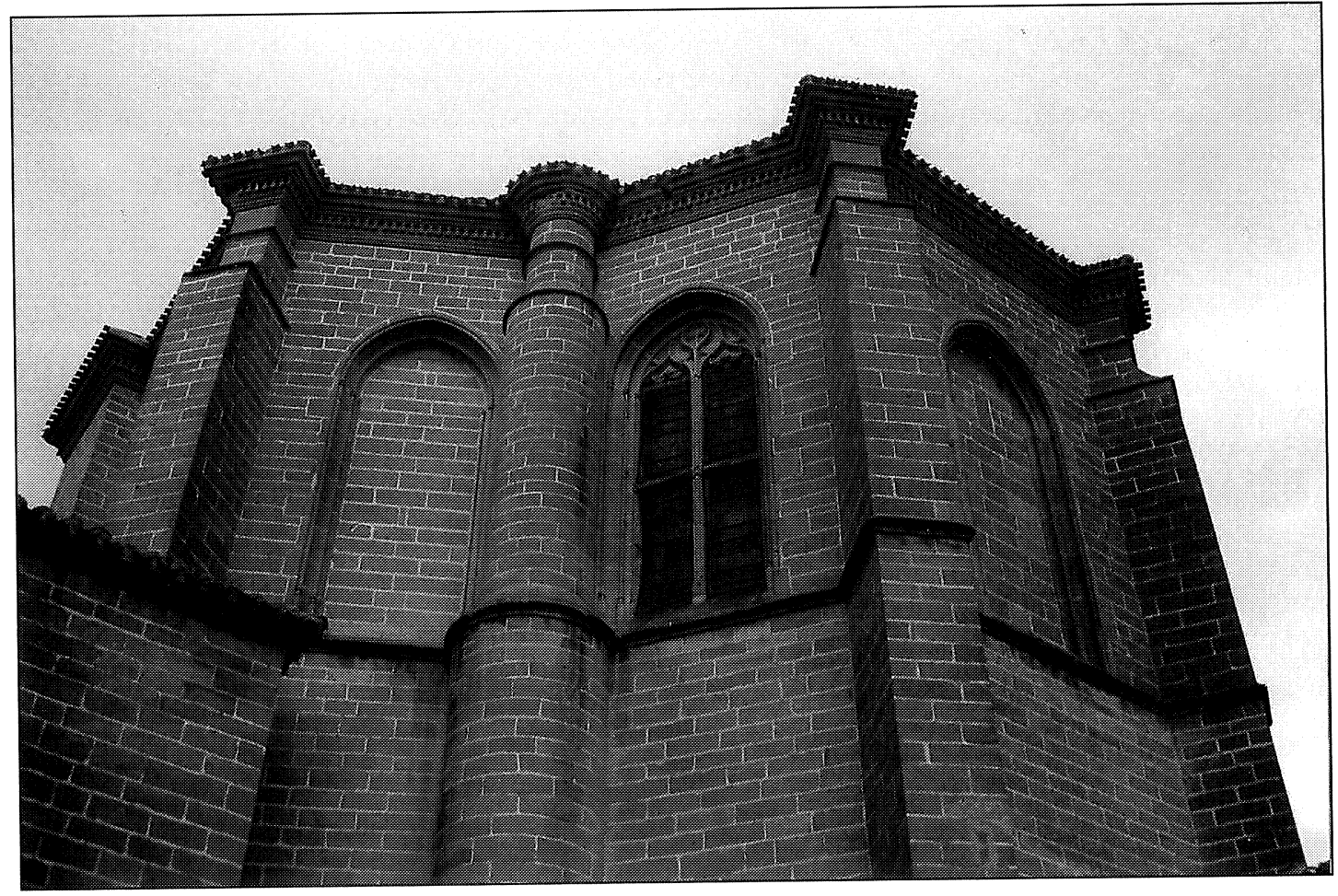

Fig. 6. Detalle de la bóveda de un ochavo en la cabecera de la iglesia monasterial de Casalarreina. Fig. 7. Cabecera de La Piedad en Casalarreina.

AEA, LXXVIII, 2005, 311, pp. 277 a 295 
lid que «la construcción y hedificación y dotación del monasterio no había quien tan congruentemente lo hiciese y las necesidades del Monasterio las pudiese suplir como sus Señorías los Condestables», por lo que se entregaba la posesión del mismo a los descendientes de la Casa de Velasco; éstos, por su parte, se comprometieron a que el edificio fuera habitado por monjas en el plazo de tres años. No tardaron en cumplir se promesa y en 1523 cedieron el edificio a su sobrina doña Isabel Alonso de Guzmán y Fernández de Velasco para que estableciese allí un monasterio de dominicas. En octubre de 1524 el prior del monasterio de San Pablo de Burgos tomaba posesión del monasterio acompañado de las primeras religiosas procedentes de Toledo (entre ellas Isabel de Velasco) ${ }^{48}$ (Figs. 6 y 7).

El único artista con taller estable en el monasterio fue Felipe de Bigarny, quien dirigía allí un grupo de entalladores entre 1515 y $1519^{49}$. Con ellos estaba un joven Juan de Rasines que el 6 de octubre de 1517 era citado como «criado» del maestro y que llegará a ser el maestro de obras de la Casa de Velasco. La existencia de este numeroso taller está relacionada con la obra de la portada de la iglesia. Las esculturas de Adán y Eva en dicha portada, (calificadas por un contemporáneo como «una cossa de las vien acauadas que pueden ser» ${ }^{50}$ ), son las mejor evidencia de la mano del maestro. Pero algunos historiadores han ido más allá al plantear la posibilidad de que Bigarny sea el autor del diseño del edificio, lo que contradice la limitada carrera de Bigarny como arquitecto ${ }^{51}$. Otros historiadores buscaron directamente a un arquitecto y nada más fácil que Juan de Rasines, el único relacionado documentalmente con la obra ${ }^{52}$, hasta que Río de la Hoz daba a conocer el dato de que desde el 15 de febrero hasta el 12 de marzo de 1516 se encontraba en Casalarreina «un maestro que es huésped de felipe» acompañado por su hijo Rodrigo: Juan Gil de Hontañón ${ }^{53}$. Durante prácticamente un mes Juan Gil permaneció en la obra y este hecho, unido a su capacitación profesional en esos años (Rasines aún no la tenía), su relación con la Casa de Velasco desde que en 1515 se convierte en el maestro de la familia, los ecos de la obra de Guas presentes en todo el edificio y la tipología empleada en la capilla mayor de la iglesia, nos llevan a pensar en él como el verdadero arquitecto del monasterio. Las nuevas responsabilidades del obispo Velasco en la sede de Palencia, donde Juan Gil trabajaba desde 1505, puede que motivasen esta visita de Hontañón en 1516 coincidiendo con el momento en que «se acabaron de cerrar las capillas altas y bajas y colaterales de ellas, y pocos días antes se había acabado la capilla capitular (de la catedral de Palencia)» ${ }^{54}$.

La capilla mayor riojana repite el modelo trebolado, como una iglesia aparte, con planta de cruz griega de brazos trapezoidales articulados en torno a un tramo cuadrado que hace las veces de capilla mayor y crucero. Los brazos de la capilla se cubren con simples terceletes que en la bóveda central se curvan antes de unirse - recurso luego empleado por Juan de Rasines-. El cuerpo de la iglesia se completa a los pies con un sotocoro cubierto con una bóveda estrellada de

\footnotetext{
${ }^{48}$ A.D. Logroño. Casalarreina, Caja 16. 24 de Octubre de 1524.

${ }^{49}$ Eran Francisco de San Gil, Guillén, Enrique «el viejo», Enrique «el mozo», Mateo Monleón, Guillén de Torres, Juan Marchicavo, Mateo, Juanico de los Mozos, otro Guillén, Enrique de Borgoña, Mateo de Picardía y Mateo Paredes. El 15 de junio de 1518 también estaban presentes en Casalarreina Juan de Valmaseda (imaginero vecino de Burgos), Juan de Cabreros, entallador, Juan de Ribero cantero, y García Gil, vecino de Ramales. (Río de la Hoz, I.: El escultor Felipe de Bigarny (h. 1490-1542). Valladolid, 2001, p. 139).

${ }^{50}$ Cadiñanos Bardeci, I.: «Felipe Bigarny, Alonso Berruguete y los sepulcros de los Condestables en Burgos», en Archivo Español de Arte, 1983, p. 351, quien da a conocer un documento de A.H.N. Inquisición, Informaciones genealógicas, Leg. 1474/3, n $^{\circ} 10$, donde descendientes del maestro recogen noticias de sus obras.

${ }^{51}$ De este aspecto nos hemos ocupado más ampliamente en Alonso Ruiz, B.: Arquitectura tardogótica..., pp. 63-64. Por su parte, Isabel del Río describe a Bigarny como un «decorador de los espacios construidos» (Río de la Hoz, I.: El escultor..., p. 132).

${ }^{52}$ Weise, G.: Studien zur Spanische Architektur..., il. 54 y Moya Valgañón, J.G.: «Convento de la Piedad de Casalarreina», en Gil de Zúñiga, R.: Monasterio de La Piedad..., pp. 49 y 286.

${ }^{53}$ Río de la Hoz, I.: El escultor..., p. 140.

${ }^{54}$ Agapito y Revilla, J.: La catedral de Palencia. 1896, p. 36.
}

$A E A$, LXXVIII, 2005, 311, pp. 277 a 295 
ocho puntas al modo de Guas en el crucero del Parral. Los pilares del sotocoro decorados con casetones hexagonales se repiten en el cuerpo alto del claustro monasterial. La estructura de este coro bajo debió inspirar a Juan Campero para solucionar el sotocoro de la capilla de Mosén Rubí de Bracamonte en Ávila.

También se relaciona con Juan Gil de Hontañón la cabecera de la iglesia de San Eutropio de El Espinar (Segovia), la primera capilla trebolada no asociada a una función funeraria. Los escasos datos que tenemos de este templo indican que estaba construido en 1542 cuando sufrió un importante incendio que obligó a reconstruir la nave en $1585^{55}$. Había sido iniciada en tiempos de Juan Guas puesto que su aparejador Ruesga frecuentó la obra en los años 80 del siglo xv ${ }^{56}$. Quizá de estos años proceda la futura relación con Juan Gil.

Fue J.D. Hoag el primero en relacionar la iglesia con Juan Gil o un joven Rodrigo, aunque Casaseca rechaza esta segunda opción. Nosotros nos inclinamos por Juan, con lo que el planteamiento de la cabecera sería anterior a 1526. La principal característica común con las otras capillas treboladas vinculadas a Hontañón (al margen del diseño mural, los soportes, etc.) radica en el sistema de unión empleado entre la cabecera y las naves que lo diferencia del usado por Guas y del que usará Juan de Rasines y que no es otro que el empleo de un tramo en forma de triángulo rectángulo.

\section{La escuela de Juan Gil de Hontañón}

A Juan Campero se debe la construcción de la Capilla de Nuestra Señora de La Anunciación, más conocida como la Capilla de Mosén Rubí de Bracamonte en el hospital de la Anunciación de Ávila, finalizada en 1544 (según consta en una inscripción sobre la ventana del ochavo norte) como capilla funeraria dentro de un conjunto hospitalario ${ }^{57}$. La fundadora, doña María de Herrera Señora de Velada y Colilla y viuda del regidor don Andrés Vázquez Dávila, redactaba su testamento en Valladolid el 2 de octubre de 1512 dotando la creación de un hospital para trece pobres, en honor de Jesucristo y sus doce apóstoles. Nombraba entonces como patrono de la misma a don Diego de Bracamonte, a quien sucedería en el cargo su hijo Mosén Rubí ${ }^{58}$.

Se ha venido señalando que su tracista eligió el modelo trebolado dado que había trabajado en El Parral, pero esto no ocurría hasta 1529 en que puso fin a la torre del monasterio jerónimo. $\mathrm{Si}$ ahondamos en su prácticamente desconocida biografía ${ }^{59}$, resulta interesante su trabajo como primer aparejador de la catedral nueva de Salamanca a las órdenes de Juan Gil de Hontañón a partir de 1512 y su labor para el cardenal Cisneros en el Convento de San Francisco de Torrelaguna, ambas actividades anteriores a 1519 en que consta ya como vecino de Ávila (probablemente lo fuese desde unos años antes). No debió permanecer mucho en la ciudad puesto que a partir de 1524 trabaja de manera asidua en Segovia, ocupado en el traslado del claustro y en

\footnotetext{
${ }_{55}$ Alonso Ruiz, B.: Arquitectura tardogótica..., p. 165.

${ }^{56}$ M. ${ }^{a}$ Blanca López Díez: Segovia en época de los Trastámara. Tesis Doctoral, U.A.M., 2002.

${ }^{57}$ La cabecera se concluyó en esa fecha y en 1557 se procedía a contratar la obra del tramo de los pies. La autoría fue dada a conocer por Parrado del Olmo, J.M.: «La capilla de Mosén Rubí de Bracamonte», en Boletín del Seminario de Arte y Arqueología, Valladolid, 1981, pp. 285-306.

${ }^{58}$ Bonet Correa, A.: «La capilla de Mosén Rubí de Bracamonte y su interpretación masónica», en Ars Longa, n. 2, 1991, p. 7. Se han ocupado de la obra: Foronda y Aguilero, M. de: «Mosén Rubí, su capilla en Ávila y su escritura de fundación», en Boletín de la Real Academia de la Historia, LXIII, 1913, pp. 332-350; Parrado del Olmo, J.M.: «La capilla de Mosén Rubí...», pp. 285-306.

${ }^{59}$ En 1529 era ayudado por su hijo homónimo quien tenía empezada a construir «una puente en la villa de Salamanca». Ambos, padre e hijo, se declaran vecinos de Ávila. (Martínez Adell, A.: «Arquitectura plateresca ...», p. 23). Los pocos datos de su biografía se recogen en el artículo de Parrado del Olmo.
} 


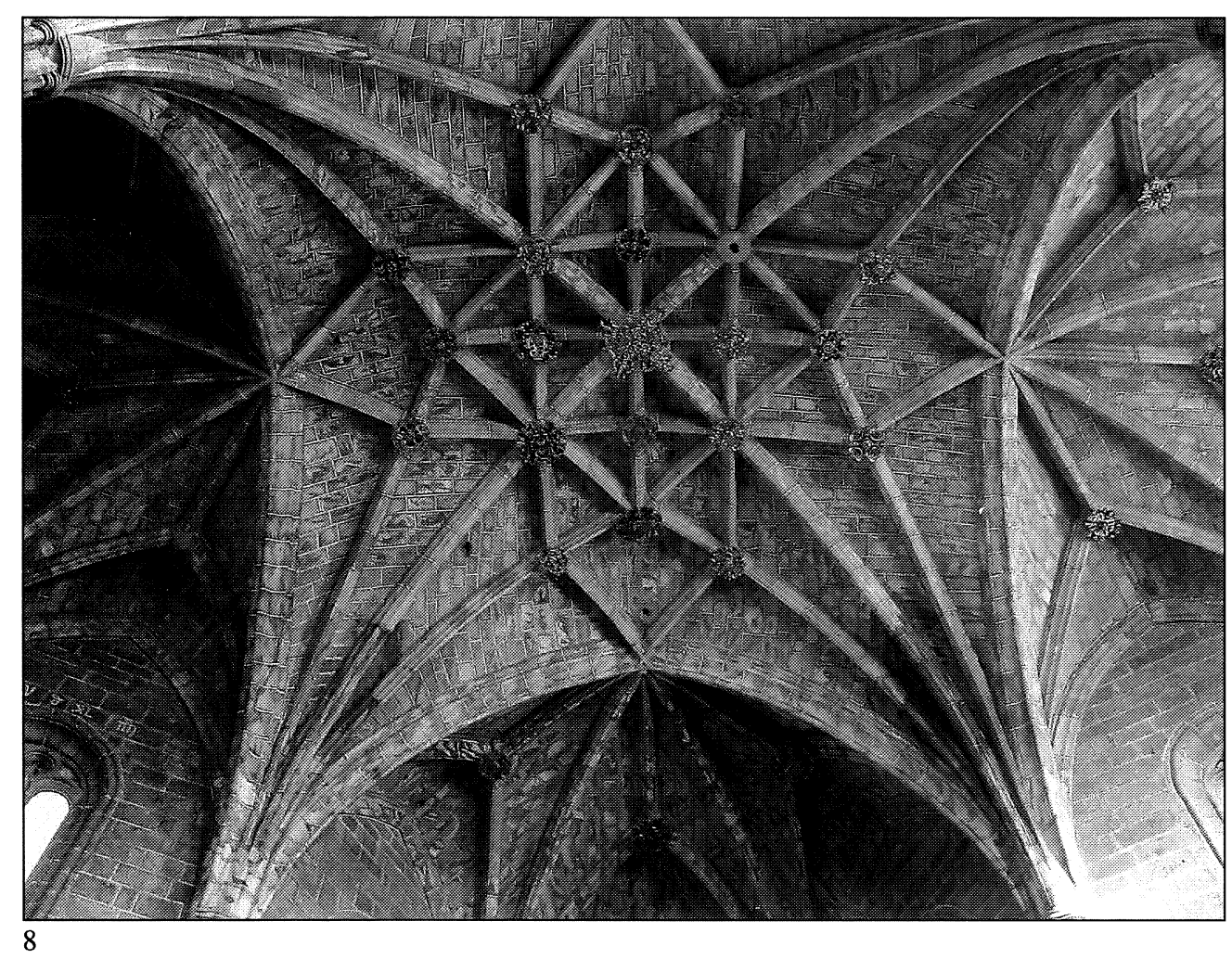

8

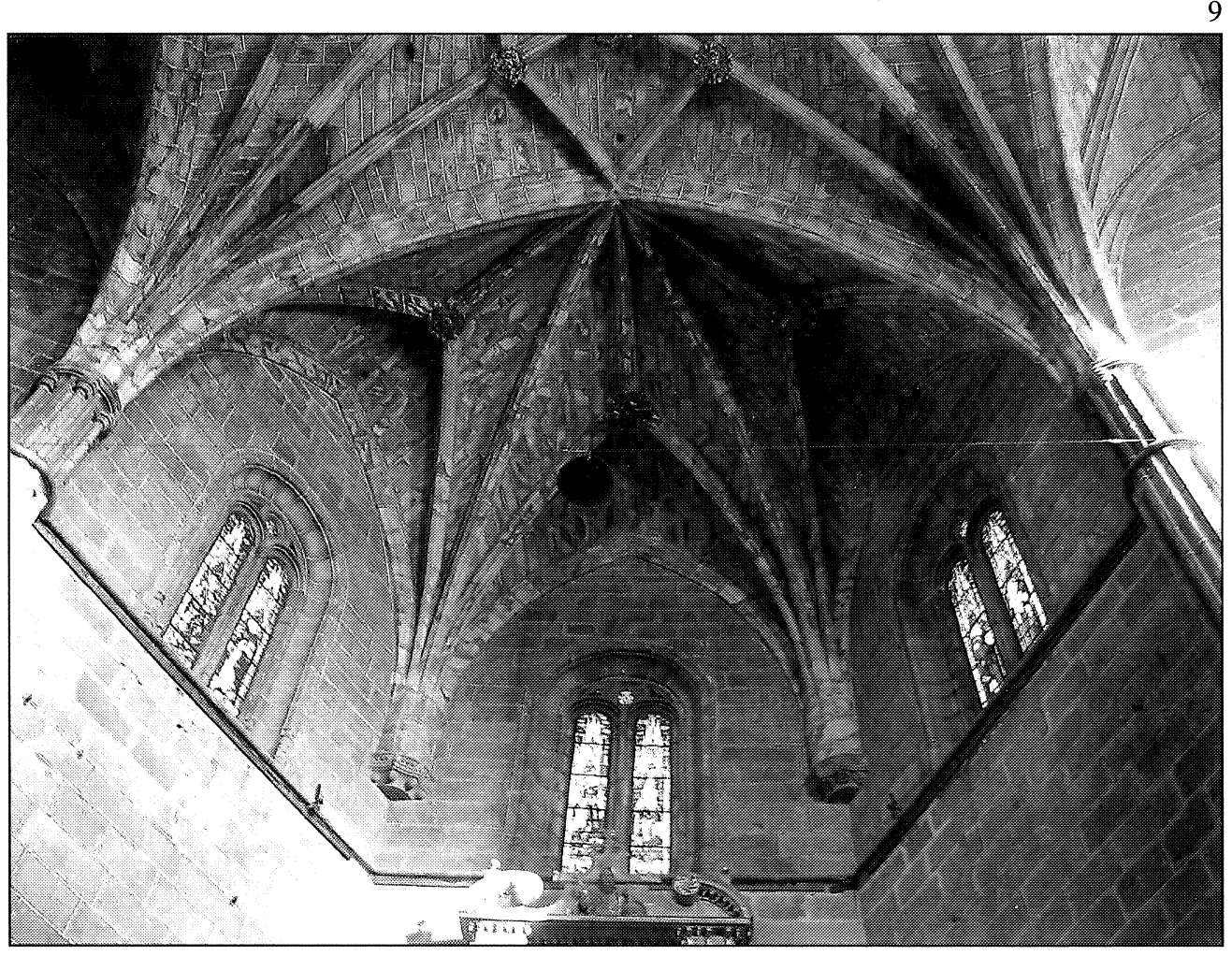

Fig. 8. Cabecera de la capilla de Mosén Rubí de Bracamonte.

Fig. 9. Detalle de los ochavos de la capilla de Mosén Rubí de Bracamonte.

$A E A$, LXXVIII, 2005, 311, pp. 277 a 295 
otras obras religiosas y civiles y ya en torno a 1530 trabaja en Medina del Campo ${ }^{60}$. El conocimiento de la obra de Juan Gil de manos del propio maestro, unido a su actividad para el cardenal -además provincial de los franciscanos observantes-, creemos que están en el germen de la capilla. Destaca el efecto cromático debido a la utilización de piedra granítica para el cuerpo de la capilla y caliza con hierro para las bóvedas, inspirado en la cercana catedral. La perfecta estereotomia de la bóveda de crucería recta (con juegos muy del gusto tardogótico como el entrecruce de los nervios del pie de gallo sobre el formero), contrasta con la solución arcaica de colocar las ménsulas sobre las que descansa las bóvedas a media altura, entre la imposta y las ventanas. (Figs. 8 y 9).

Fue Juan de Rasines, el entonces maestro de obras del Condestable de Castilla sucediendo en el puesto a Hontañón, el siguiente en hacer su propia interpretación del modelo trebolado (que había conocido en la iglesia monasterial de Casalarreina). Lo empleó la primera vez que diseñó un templo de nueva planta. Corría el año 1526 cuando se iniciaba la Colegiata de Santa María del Mercado en Berlanga de Duero (Soria) ${ }^{61}$. La importancia del proyecto radicaba en su profundo significado político al corresponderse a una clara intención de asentamiento en la villa por parte del matrimonio Velasco-Tovar, condestables de Castilla desde 1512, propiciando una profunda transformación urbana al ampliarse la antigua fortaleza, construirse un palacio ducal, una nueva colegiata con su propia plaza - llamada de San Andrés- (para lo cual se derriba parte del antiguo caserío) y una plaza mayor al derribarse la antigua iglesia parroquial que allí se encontraba. El éxito de la obra radica en la hábil combinación del espacio centralizado de la cabecera con un templo con naves a la misma altura, lo que convierte a esta iglesia en un caso excepcional dentro de la arquitectura religiosa de comienzos del siglo xvI, como ya resaltaron arquitectos como Francisco Sabatini o historiadores como Weise ${ }^{62}$. Pero, de nuevo, la fórmula trebolada en su concepción original no cumplía la función funeraria; será a partir de 1545 cuando el marqués don Juan de Tovar decida enterrarse en la capilla mayor.

La colocación de la primera piedra del nuevo templo se realizó en una solemne ceremonia el 22 de junio de 1526, por lo que suponemos que fuese trazada a finales de 1525 y existe constancia documental de que el 9 de enero de 1530 se hizo solemne bendición del templo por don Cristóbal de Barrionuevo, Obispo de Tagaste, aunque el templo aún no estaba, ni mucho menos, finalizado. El condestable don Íñigo murió en 1528 sin ver su obra concluida; su mujer doña María de Tovar en su testamento de noviembre de 1527 se refería a la iglesia «que agora se hace» ${ }^{63}$. De hecho, aún quedaba obra por hacer en la colegial como demuestra el que en 1544 los dos hijos del matrimonio, el condestable don Pedro y su hermano el marqués de Berlanga, se obligaban a entregar a la fábrica la cantidad anual de 100.000 maravedíes «hasta dar concluya y cerrada de boveda la fabrica desta yglesia colegial» ${ }^{64}$. Al no conservarse el libro de fábrica, desconocemos cuando se concluyó el templo y quienes fueron los artífices que intervinieron en la obra. Sabemos, eso sí, que en Berlanga trabajaban canteros habituales en la

\footnotetext{
${ }^{60}$ En 1533 se le cita como vecino de Medina en la información del pleito sobre la obra de la capilla del deán Cepeda en San Francisco de Zamora; entonces el cantero Juan de la Cámara lo cita entre los mejores maestros. Martí y Monsó, J.: «La capilla del Deán don Diego Vázquez de Cepeda en el Monasterio de San Francisco de Zamora», en Boletín de la Sociedad Castellana de Excursiones, V, 1907, p. 117.

${ }^{61}$ La última revisión en Alonso Ruiz, B.: Arquitectura tardogótica..., pp. 197-206, con la bibliografía anterior.

${ }^{62}$ Cuando fue a reconocer en la Catedral del Burgo de Osma la Capilla de Palafox visitó Berlanga y exclamó al contemplar la Colegiata « ¿en donde hallaría este arquitecto el modelo de una obra tan bien entendida y estudiada? ¡Ella sola honraría la capital de un reino!» (Rabal, N.: España, sus monumentos y sus artes. Su naturaleza e historia. Soria. Barcelona, 1889. (Reedic. Soria, 1980), p. 381). Weise escribía en 1953 que «El intento de armonizar el sistema de tres naves de igual altura con la tendencia a una orientación central, no ha encontrado en ninguna otra construcción una solución tan rica y completa». (Weise, G.: Die Spanische Hallenkirchen der Spätgotik und der Renaissance. Tubinga, 1953, p. 19).

${ }^{63}$ A.H.N. Secc. Nobleza. Frías. Leg. 308, exp. 8i. Testamento de María de Tovar. Se trata de su tercer testamento ya que existen al menos dos anteriores: uno fechado el 18 de septiembre de 1521 y otro del 8 de agosto de 1523.

${ }^{64}$ Martínez Frías, J.M.: El Gótico en Soria. Arquitectura y escultura monumental. Salamanca, 1980, p. 370.
} 


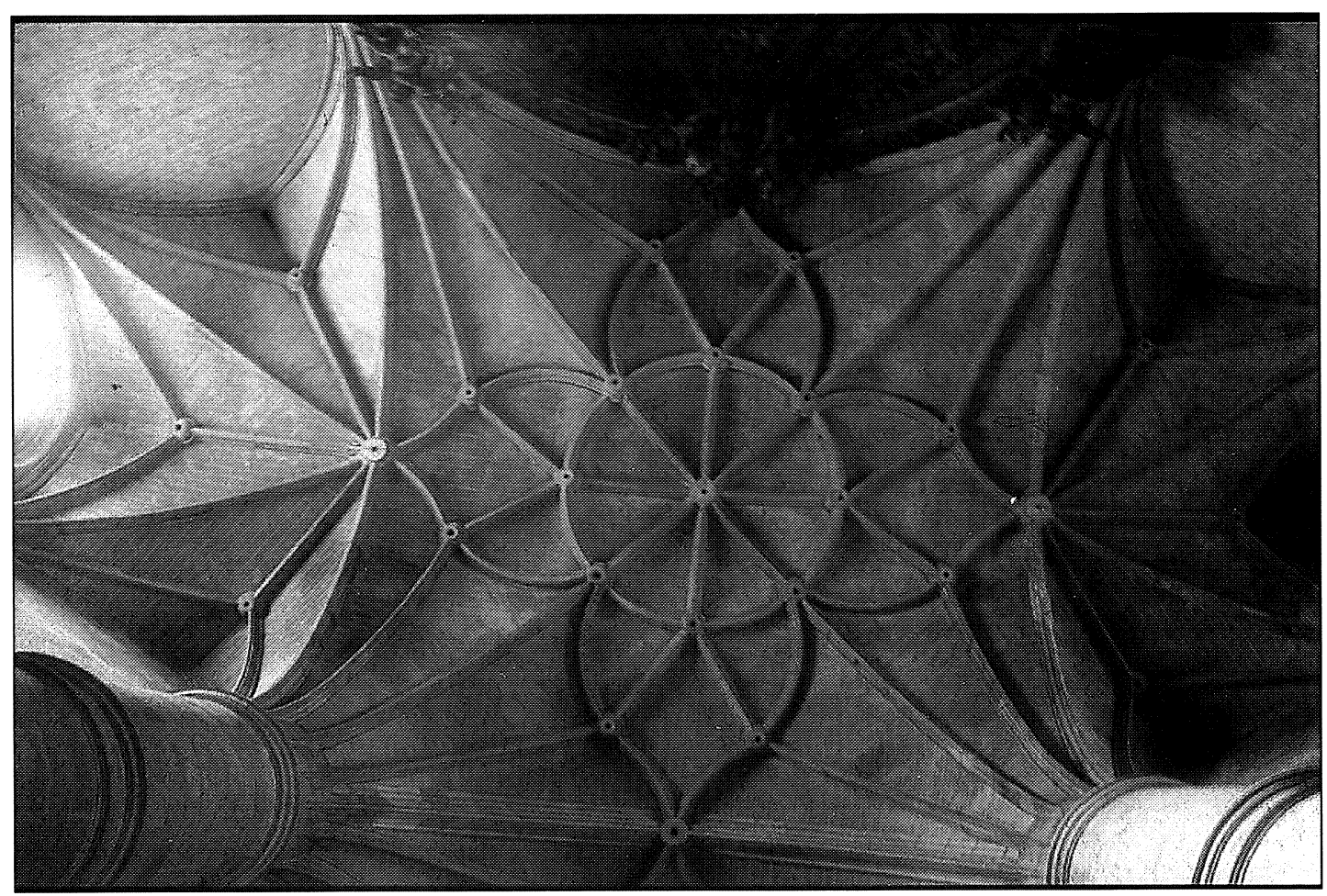

Fig. 10. Cabecera de la Colegiata de Berlanga de Duero.

cuadrilla de Rasines y entalladores del taller de Bigarny: el maestro Pedro de Holanda está documentado en 1527, Andrés de Nájera en 1528 y en 1549 se declaraba vecino de Berlanga el cantero natural de Rasines Rodrigo Ezquerra Villa cuando contrataba la continuación de la entonces Colegiata de San Pedro en Soria (Fig. 10).

El análisis de la planta de Berlanga de Duero relaciona a Juan de Rasines con la cabecera de la iglesia de San Vicente de la Maza en Guriezo (Cantabria) ${ }^{65}$, obra de la que no se tienen referencias constructivas hasta abril de 1592. En esa fechas Juan de Zorlado Ribero contrataba el primer tramo de la nave, evidenciando que la cabecera correspondía a un periodo constructivo anterior. La historia constructiva del templo, que se alarga hasta entrado el siglo XVIII ${ }^{66}$, ilustra el tesón de los mayordomos de la iglesia quienes fueron realizando, una tras otra, todas las ampliaciones necesarias para completar el plan definitivo de la iglesia con una coherencia estilística que evidencia la existencia de un proyecto preconcebido. Este plan debió realizarse con posterioridad a la Colegiata de Berlanga de Duero ya que la planta de Guriezo es una simplificación de la soriana, eliminándose las naves colaterales de capillas entre contrafuertes y los dos tramos de los pies. Son similares los ochavos de la cabecera, el desarrollo de los pilares, el diseño de bóvedas en la cabecera y las naves, la preferencia por los tramos cuadrados, la forma de solucionar la unión entre la cabecera y las naves a través de tramos triangulares de bóveda de cruceros o el uso del rampante redondo. Pero a pesar de todo ello, otros elementos distan mucho del estilo rasinesco explicables desde la perspectiva de la materialización del proyecto durante casi dos siglos.

\footnotetext{
${ }^{65}$ Polo Sánchez, J.J.: «Una iglesia de salón cántabra en el siglo xvi. La parroquial de San Vicente de la Maza (Guriezo)», en Población y sociedad en la España cantábrica durante el siglo XVII. Santander, 1985, pp.273-298.

${ }^{66}$ Puede seguirse en Alonso Ruiz, B.: Arquitectura tardogótica..., pp. 271 y ss.
} 
Dos años más tarde del comienzo de la Colegiata de Berlanga de Duero se proyectaba la iglesia segoviana de San Sebastián en Villacastín, realizada por Rodrigo Gil de Hontañón a partir de $1551^{67}$. Las semejanzas entre la obra soriana y la segoviana nos indican que Juan de Rasines y Rodrigo Gil se alimentaban de una fuente común que no era otra que la obra de Juan Gil, maestro del primero y padre de Rodrigo. Extraña sin embargo que Rodrigo Gil, con una larguísima lista de obras en iglesias parroquiales castellanas, no volviera a usar el modelo trebolado optando generalmente por el empleo de sencillas cabeceras ochavadas, con menores complicaciones constructivas, como demuestra en su manuscrito de arquitectura compilado por Simón García entre 1681 y $1683^{68}$.

$\mathrm{La}$ arquitectura «a la romana» abandonó el modelo trebolado para sus construcciones centralizadas. Rara excepción es la de la cabecera de la iglesia parroquial de Santiago en Jumilla (Granada), construida por Jerónimo Quijano en 1538 con función funeraria. La formación de Quijano junto a Felipe de Bigarny por tierras burgalesas y riojanas nos explica su conocimiento del modelo trebolado. Ahora las tres bóvedas de horno reemplazan a los ochavos góticos como ocurre también en la cabecera de la pequeña parroquial burgalesa de Villasidro, en la que la cabecera triconque no se trasdosa al exterior. Quizá este último ejemplo tenga que ver con la estela de Rodrigo Gil de Hontañón, muy activo por esa área burgalesa; de ser así de nuevo encontraríamos las raíces en el trabajo de Juan Gil de Hontañón, eco de Juan Guas y ese primer ejemplo segoviano.

\footnotetext{
${ }^{67}$ Hoag, J.D.: Rodrigo Gil de Hontañón.., p. 78. Sobre esta obra véase también Weise, G.: Die Spanische Hallenkirchen..., p. 18; Casaseca Casaseca, A.: Rodrigo Gil de Hontañón (Rascafria, 1500- Segovia, 1577). Salamanca, 1988, pp. 49 y ss.; Alonso Ruiz, B.: Arquitectura tardogótica..., pp. 132-133, 169.

${ }^{68}$ Sobre el manuscrito véase Camón Aznar, J.: «La intervención de Rodrigo Gil de Hontañón en el manuscrito de Simón García», en Archivo Español de Arte, 1941, XIV, pp. 300-315. De investigar sobre Simón García se ha ocupado Rupérez Almajano, N.: «Anotaciones sobre la vida y obra del arquitecto Simón García», en Archivo Español de Arte, 1998, n. 281, 1998, pp. 68-75. Existen varias ediciones del manuscrito como la de Camón Aznar de 1941 o la de Pereda de la Reguera de 1951. La edición utilizada es la del Colegio Oficial de Arquitectos de Valladolid de 1991, con estudios introductorios a cargo de Bonet Correa y Chanfón Olmos.
} 